\title{
An Investigation of Hydrothermal Routes to Mixed-Metal Cerium Titanium Oxides and Metal Oxidation State Assignment using XANES
}

Christopher S. Wright, ${ }^{\mathrm{a}}$ Richard I. Walton, ${ }^{\mathrm{a}^{*}}$ David Thompsett ${ }^{\mathrm{b}}$ and Janet Fisher ${ }^{\mathrm{b}}$

\section{Supplementary Information}

S1: Indexed powder X-ray diffraction data for $\mathrm{NaCeTi}_{2} \mathrm{O}_{6}(P n m a, a=5.4517(8)$ $\AA, b=7.7292(6) \AA, c=5.4573(3) \AA)$.

\begin{tabular}{|c|c|c|c|c|}
\hline h & $\mathbf{k}$ & l & Calculated $2 \theta$ & Observed $2 \theta$ \\
\hline 0 & 2 & 0 & 23.017 & \multirow{2}{*}{23.0048} \\
\hline 1 & 0 & 1 & 23.046 & \\
\hline 1 & 2 & 1 & 32.798 & \multirow{3}{*}{32.7744} \\
\hline 2 & 0 & 0 & 32.813 & \\
\hline 0 & 0 & 2 & 32.826 & \\
\hline 0 & 3 & 1 & 38.651 & \multirow{3}{*}{38.5393} \\
\hline 2 & 1 & 1 & 38.683 & \\
\hline 1 & 1 & 2 & 38.691 & \\
\hline 2 & 2 & 0 & 40.462 & \multirow{2}{*}{40.4422} \\
\hline 0 & 2 & 2 & 40.473 & \\
\hline 0 & 4 & 0 & 47.034 & \multirow{2}{*}{47.0212} \\
\hline 2 & 0 & 2 & 47.097 & \\
\hline 1 & 4 & 1 & 53.004 & \multirow{4}{*}{53.0439} \\
\hline 2 & 2 & 2 & 53.047 & \\
\hline 3 & 0 & 1 & 53.053 & \\
\hline 1 & 0 & 3 & 53.070 & \\
\hline 3 & 2 & 1 & 58.570 & \multirow{2}{*}{58.5857} \\
\hline 1 & 2 & 3 & 58.585 & \\
\hline 0 & 5 & 1 & 62.450 & \multirow{4}{*}{62.6074} \\
\hline 0 & 3 & 3 & 62.509 & \\
\hline 3 & 1 & 2 & 62.522 & \\
\hline 2 & 1 & 3 & 62.531 & \\
\hline 2 & 4 & 2 & 68.757 & \multirow{3}{*}{68.7604} \\
\hline 4 & 0 & 0 & 68.792 & \\
\hline 0 & 0 & 4 & 68.820 & \\
\hline
\end{tabular}




\begin{tabular}{|c|c|c|c|c|}
\hline 0 & 6 & 0 & 73.530 & \multirow{6}{*}{73.5716} \\
\hline 3 & 4 & 1 & 73.583 & \\
\hline 1 & 4 & 3 & 73.596 & \\
\hline 4 & 2 & 0 & 73.611 & \\
\hline 3 & 0 & 3 & 73.637 & \\
\hline 0 & 2 & 4 & 73.639 & \\
\hline 1 & 6 & 1 & 78.246 & \multirow{4}{*}{78.3357} \\
\hline 3 & 2 & 3 & 78.340 & \\
\hline 4 & 0 & 2 & 78.341 & \\
\hline 2 & 0 & 4 & 78.362 & \\
\hline 2 & 6 & 0 & 82.879 & \multirow{4}{*}{82.9284} \\
\hline 0 & 6 & 2 & 82.886 & \\
\hline 4 & 2 & 2 & 82.965 & \\
\hline 2 & 2 & 4 & 82.985 & \\
\hline 4 & 4 & 0 & 87.517 & \multirow{2}{*}{87.5501} \\
\hline 0 & 4 & 4 & 87.544 & \\
\hline 2 & 6 & 2 & 92.047 & \multirow{4}{*}{92.0209} \\
\hline 3 & 4 & 3 & 92.104 & \\
\hline 5 & 0 & 1 & 92.130 & \\
\hline 1 & 0 & 5 & 92.170 & \\
\hline 3 & 6 & 1 & 96.627 & \multirow{6}{*}{96.7074} \\
\hline 1 & 6 & 3 & 96.641 & \\
\hline 4 & 4 & 2 & 96.682 & \\
\hline 2 & 4 & 4 & 96.702 & \\
\hline 5 & 2 & 1 & 96.706 & \\
\hline 1 & 2 & 5 & 96.747 & \\
\hline 4 & 0 & 4 & 106.078 & 106.0206 \\
\hline 1 & 8 & 1 & 110.705 & \multirow{4}{*}{110.6971} \\
\hline 4 & 6 & 0 & 110.776 & \\
\hline 0 & 6 & 4 & 110.805 & \\
\hline 5 & 4 & 1 & 110.831 & \\
\hline 2 & 8 & 0 & 115.678 & \multirow{7}{*}{115.8109} \\
\hline 0 & 8 & 2 & 115.685 & \\
\hline 3 & 6 & 3 & 115.770 & \\
\hline 6 & 0 & 0 & 115.851 & \\
\hline 5 & 2 & 3 & 115.857 & \\
\hline 3 & 2 & 5 & 115.887 & \\
\hline 0 & 0 & 6 & 115.918 & \\
\hline
\end{tabular}




\section{S2: XPS data}

(i) $\mathrm{NaCeTi}_{2} \mathrm{O}_{6} \mathrm{Ti} 2 p$ region

Ti2p 40

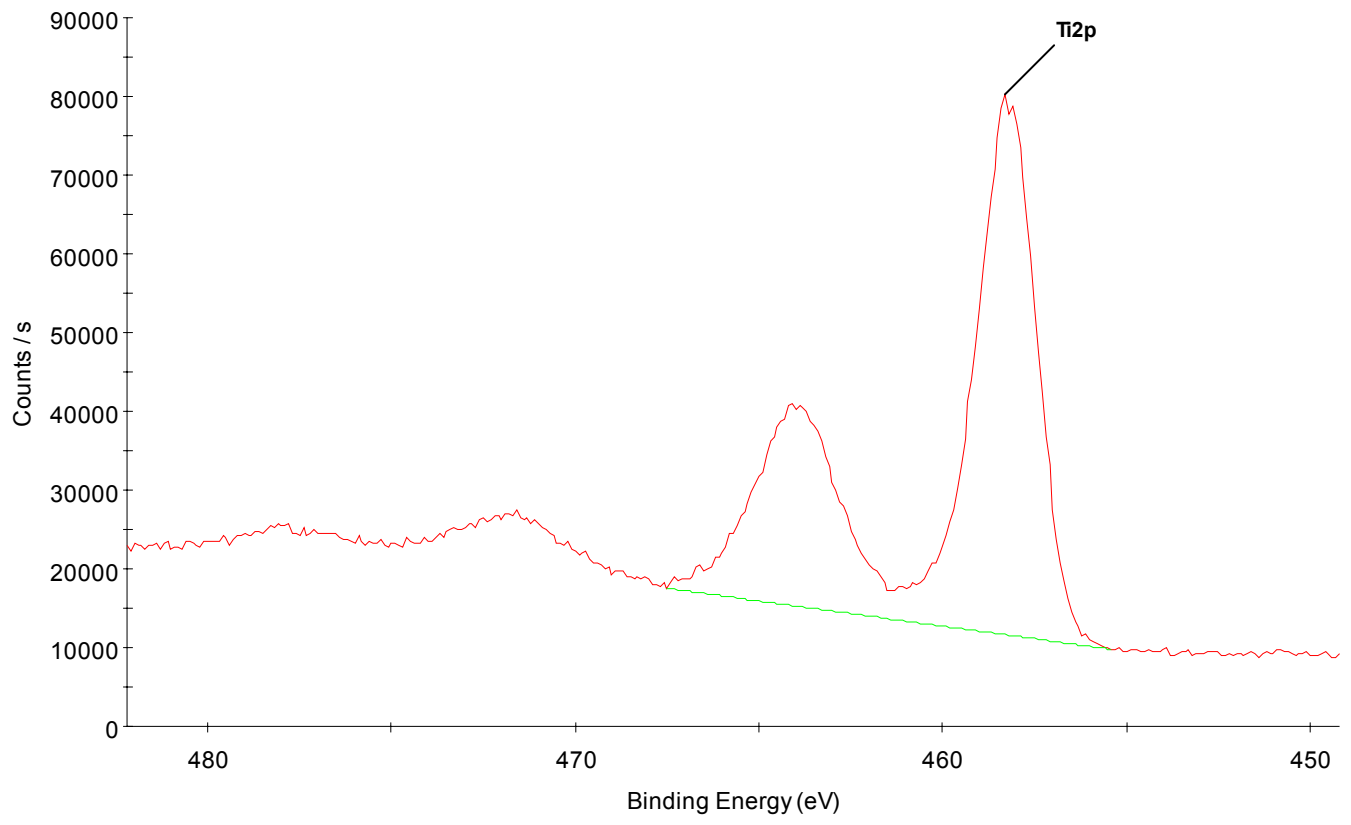

(ii) $\mathrm{NaCeTi}_{2} \mathrm{O}_{6} \mathrm{Ce} 3 d$ region

Ce3d 40

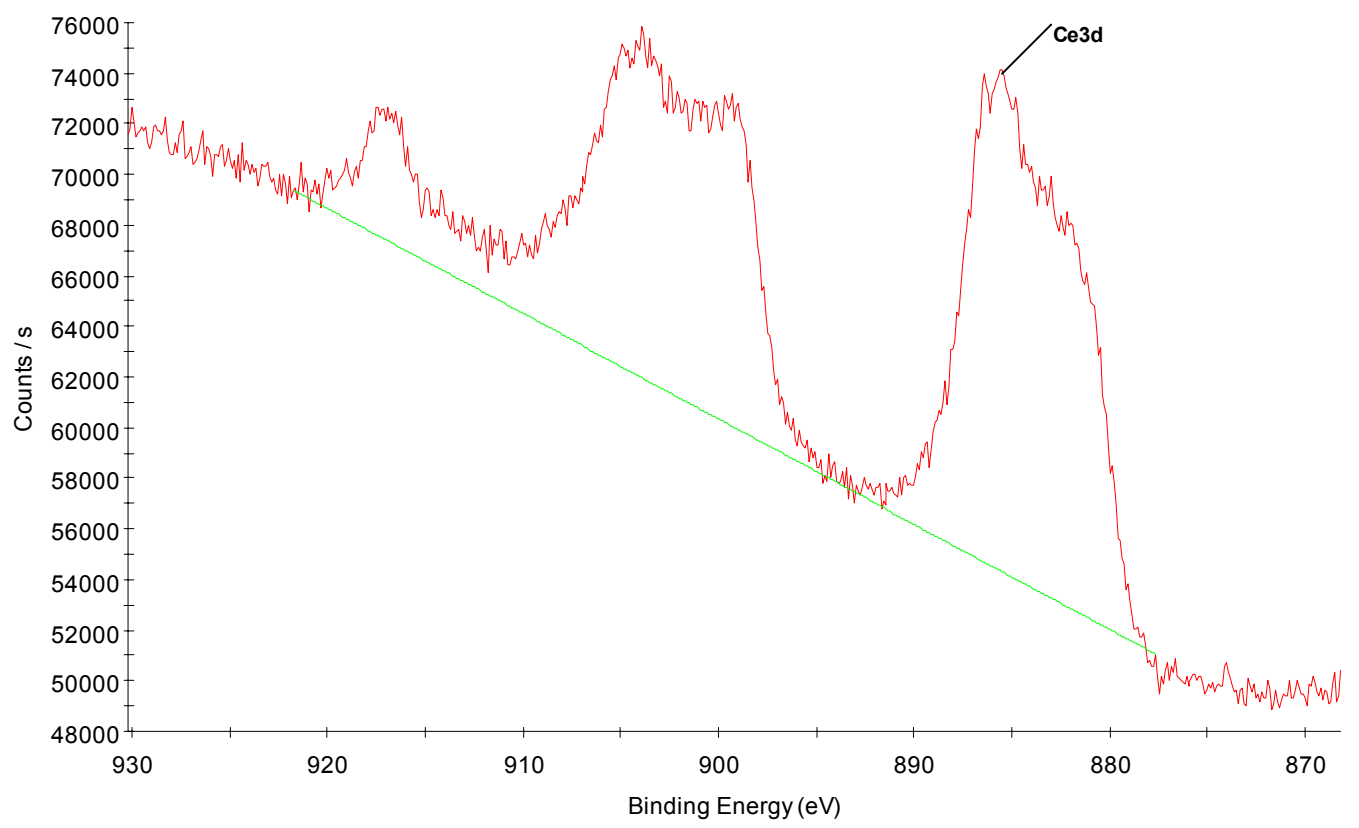


(iii) $\mathrm{CeO}_{2} \mathrm{Ce} 3 d$ region

Ce3d 40

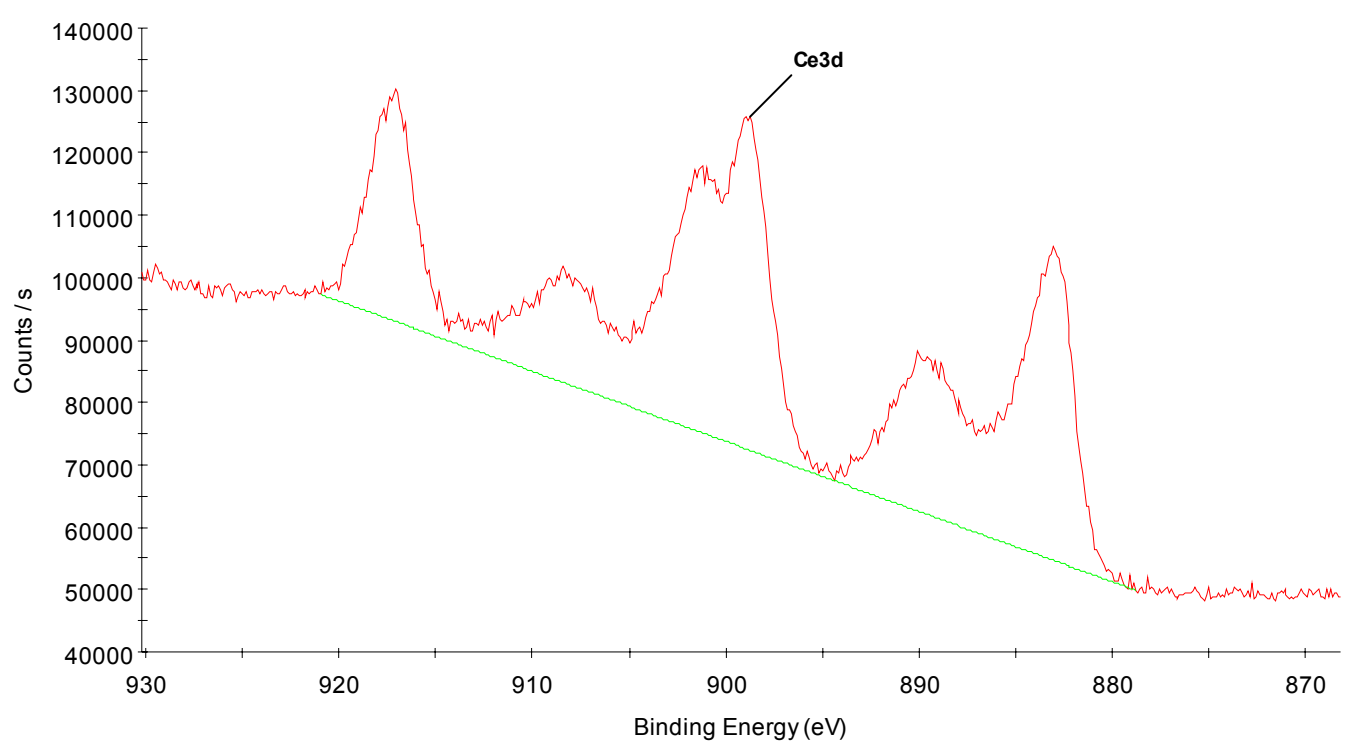

